\title{
The effect of body mass index, lower extremity performance, and use of a private car on incident life-space restriction: a two-year follow-up study
}

Taishi Tsuji $^{1 *}$ (D), Merja Rantakokko², Erja Portegijs², Anne Viljanen ${ }^{2}$ and Taina Rantanen ${ }^{2}$

\begin{abstract}
Background: The purpose of the study was to explore the single and combined contributions of body mass index (BMI) and lower extremity performance as modifiable physical factors, and the influence of use of a private car as an environmental factor on prevalent and incident life-space restriction in community-dwelling older people.

Methods: Community-dwelling people aged $75-90$ years $(n=823)$ participated in the Life-Space Mobility in Old Age (LISPE) two-year follow-up study. Participants who reported that the largest life-space area they had attained, without aid from any device or another person, was the neighborhood or less were considered to have life-space restriction. Incident life-space restriction was the endpoint of Cox's proportional hazard model. BMl, lower extremity performance (Short Physical Performance Battery, SPPB), and use of a private car were predictors.

Results: At baseline, people who had both obesity (BMI $\geq 30.0$ ) and impaired lower extremity performance (SPPB 0-9) had a higher prevalence of life-space restriction (prevalence ratio 3.6, 95\% confidence interval, Cl, 2.0-6.3) compared to those with normal weight (BMI 23.0-24.9) and intact physical performance (SPPB 10-12). The 581 people without life-space restriction at the baseline contributed 1033 person-years during the twoyear follow-up. Incident life-space restrictions were reported by $28.3 \%$ participants. A higher hazard ratio (HR) for incident life-space restriction was observed in subjects having both obesity and impaired lower extremity performance ( $\mathrm{HR} 3.6,95 \% \mathrm{Cl}, 1.7-7.4$ ), impaired lower extremity performance only ( $\mathrm{HR} 1.9,95 \% \mathrm{Cl} 0.9-4.1$ ), and obesity only (HR 1.8,95\% Cl, 0.9-3.5) compared to those with normal weight and intact performance. Private car passengers (HR 2.0, 95\% Cl, 1.3-3.0) compared to car drivers had a higher risk of life-space restriction. All models were adjusted for age, sex, chronic diseases, and education.
\end{abstract}

Conclusions: Older people with impaired lower extremity performance have an increased risk of incident life-space restriction especially if combined with obesity. Also, not driving a car renders older people vulnerable to life-space restriction.

Keywords: Mobility limitation, Obesity, Physical performance, Aging

\footnotetext{
*Correspondence: tsuji.t@chiba-u.jp

${ }^{1}$ Center for Preventive Medical Sciences, Chiba University, 1-8-1 Inohana,

Chuo Ward, Chiba City, Chiba 260-8670, Japan

Full list of author information is available at the end of the article
}

(c) The Author(s). 2018 Open Access This article is distributed under the terms of the Creative Commons Attribution 4.0 International License (http://creativecommons.org/licenses/by/4.0/), which permits unrestricted use, distribution, and reproduction in any medium, provided you give appropriate credit to the original author(s) and the source, provide a link to the Creative Commons license, and indicate if changes were made. The Creative Commons Public Domain Dedication waiver (http://creativecommons.org/publicdomain/zero/1.0/) applies to the data made available in this article, unless otherwise stated. 


\section{Background}

The maintenance of good mobility is vital to attaining active aging, being closely linked to physical and psychological health status and quality of life [1, 2]. Life-space mobility refers to the spatial extent of the actual mobility performance, which depends on the balance between older adults' internal physiologic capacity and the external challenges and resources encountered in their daily environment [3]. Previous cross-sectional studies have revealed that life-space mobility is positively associated with physical [4-6] and psychological health [4] and quality of life [7, 8]. Furthermore, low life-space mobility predicts future falls [9], incident activities of daily living (ADL) disability [10], a rapid decline in cognitive function [11], health care utilization [12], and premature death [13]. Few reports have investigated the factors that may induce the incidence of life-space restriction. To date, hearing difficulties [14], low executive function [15], and frailty [16] have been reported as factors causing life-space restriction.

Life-space mobility considers the size of the spatial area (bedroom, home, yard outside home, neighborhood, town, distant locations) a person purposely moves through in daily life and the frequency of travel within a specific time and needs for assistance for that travel [4]. Movement through smaller life-space areas is more likely to occur using active forms of transportation, such as walking. In turn, traveling longer distances is more dependent on using a car or other modes of passive transportation [17]. Several cross-sectional studies have suggested that driving a car is associated with a larger life-space [18-20]. Consequently, the absence of a private car, which can be driven at will, may be a crucial environmental factor that negatively affects life-space.

Body mass index (BMI) and lower extremity performance are modifiable physical characteristics. Earlier studies have indicated that low life-space mobility is more widespread among very obese $\left(B M I \geq 35.0 \mathrm{~kg} / \mathrm{m}^{2}\right)$ community-dwelling older individuals $[5,21]$. The lower extremity performance of older individuals contributes substantially to the variability in life-space mobility [46]. Portegijs et al. [6] reported that poor balance, walking speed, and chair standing test performance were associated with reduced life-space mobility. Obesity and poor lower extremity performance may cause life-space restriction, which in turn, may result in a vicious cycle of increasing body weight and decreasing performance.

The present study aimed to explore the single and combined contributions of BMI and lower extremity performance and the use of a private car on incident life-space restriction in community-dwelling older people.

\section{Methods}

\section{Study design and participants}

The Life-Space Mobility in Old Age (LISPE) project, a two-year prospective cohort study, included 848 community-dwelling individuals aged 75-90 years residing in the municipalities of Jyväskylä and Muurame, Finland. The participants were recruited from a random sample drawn from the national population register. The inclusion criteria were a willingness to participate, community-dwelling in the study area, and ability to communicate. Participants were interviewed in their homes during spring 2012 and followed up by telephone one (mean $362 \pm 9$ days) and 2 years (mean $721 \pm 8$ days) after the baseline assessment. The recruitment and study methods, including nonrespondents, have been previously published [3].

Figure 1 shows the procedure for sample selection in our study. Of the baseline participants, those with missing data pertaining to BMI or lower extremity performance $(n=25)$ were excluded from the cross-sectional analyses leaving 823 participants. After excluding participants with life-space restriction $(n=226), 597$ participants (262 male and 335 female) were included in the present longitudinal analyses.

\section{Measurements \\ Life-space mobility}

Life-space mobility was assessed with the 15-item University of Alabama at Birmingham Study of Aging Life-Space Assessment [4] in a face-to-face interview at the baseline and telephone interviews at the 1 st and 2 nd follow-ups. Participants reported how many days a week they had attained each life-space level ( 0 , bedroom; 1 , other rooms; 2 , outside home; 3 , neighborhood; 4, town; 5 , beyond town) during the preceding 4 weeks and whether they needed help from another person or assistive devices. When the largest life-space area attained without assistance from any device or another person was the neighborhood or less (i.e., maximal independent life-space score $\leq 3$ ), subjects were considered to have life-space restriction. Subjects admitted to institutional care were also assigned incident life-space restriction.

\section{Body mass index}

Self-reported body height and weight were obtained at the baseline. BMI was calculated as weight $(\mathrm{kg})$ divided by height squared $\left(\mathrm{m}^{2}\right)$. We classified participants as obese $\left(\geq 30.0 \mathrm{~kg} / \mathrm{m}^{2}\right)$ and overweight $\left(25.0-29.9 \mathrm{~kg} / \mathrm{m}^{2}\right)$ based on World Health Organization (WHO) guidelines [22]. We categorized those participants as normal weight $\left(23.0-24.9 \mathrm{~kg} / \mathrm{m}^{2}\right)$ and low weight $\left(<23.0 \mathrm{~kg} / \mathrm{m}^{2}\right)$ based on the Mini Nutritional Assessment [23]. As only seven of the participants met the WHO criteria for underweight $\left(<18.5 \mathrm{~kg} / \mathrm{m}^{2}\right)$ in the longitudinal analyses. 


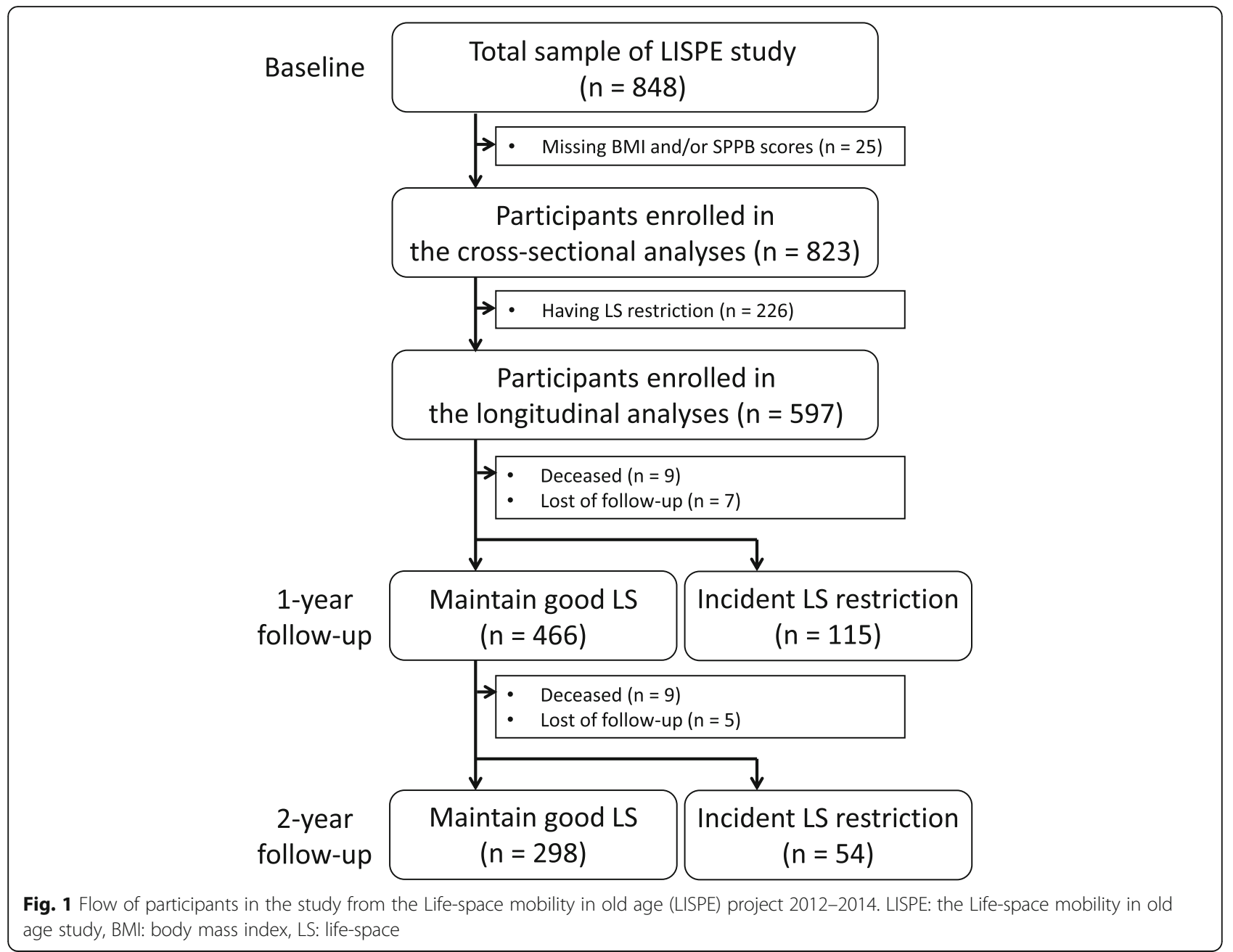

\section{Lower extremity performance}

We objectively evaluated lower extremity performance using the Short Physical Performance Battery (SPPB) [24] at baseline. SPPB comprises three tests assessing standing balance, walking speed over $2.44 \mathrm{~m}$, and five timed chair rises. Each task was scored 0-4 points according to established age- and sex-specific cutoff points [25]. A sum score was calculated (range, 0-12). When at least two tests were completed the result was included in the analyses and being scaled to represent the range. Higher scores indicated better performance. We categorized the participants as having intact (10-12) or impaired (0-9) physical performance.

\section{Use of a private car}

At the baseline, participants were asked how often they drive a car or travel by car as a passenger. The response options were daily or almost daily, a few times a week, a few times a month, a few times a year, less than once a year, and never. To be categorized as a car driver, or a private car passenger, participants needed to report using a private car at least on a monthly basis. In case they reported both drivers and being a passenger, the more frequent role was selected for the categorization. If the frequency of driving and traveling as a passenger were equal, the participant was categorized as a car driver. If the participant reported using a private car less than monthly, the person was categorized as not using a private car.

\section{Covariates}

Information regarding age and sex was derived from the national population register. Years of education was self-reported. The number of chronic diseases was calculated from a list of 22 self-reported, physician-diagnosed chronic diseases (asthma, chronic obstructive pulmonary disease, chronic bronchitis, myocardial infarction, coronary heart disease, heart failure, hypertension, stroke, thrombosis, rheumatic arthritis, osteoarthritis, chronic back pain or problems, chronic neck pain or problems, cataract (not surgically repaired), glaucoma, macular degeneration, hearing disorders, diabetes mellitus, 
malignant cancer, Parkinson's disease, Alzheimer's disease or dementia, depression or other psychiatric disorder) and an additional open-ended question concerning any other physician-diagnosed chronic conditions [6].

\section{Statistical analyses}

Group differences in baseline characteristics were investigated using ANOVA, chi-square, Kruskal-Wallis, and Mann-Whitney $U$ tests. The main outcome of this study was incident life-space restriction. A multivariate Poisson regression analysis was conducted to confirm the cross-sectional association of each BMI and SPPB category and the use of a private car with the prevalence of life-space restriction. The results were presented as prevalence ratios (PRs) with 95\% confidence intervals (CIs). Because the percentages of individuals with life-space restriction $(27.5 \%)$ were $>10 \%$, the adjusted odds ratio derived from logistic regression could no longer approximate the PR [26]. Cox's proportional hazards models were used to test the longitudinal association of each BMI and SPPB category and the use of a private car with incident life-space restriction. Ties were handled using the Breslow method. The results were presented as hazard ratios (HRs) with 95\% CIs. The follow-up period for each participant was defined from the baseline examination to the time point of the first incidence of life-space restriction, the time point of death, or the last study contact, whichever came first (i.e., 1st or 2nd follow-up) to calculate person-years. Five models were constructed in both the cross-sectional and longitudinal analyses. Model 1 and 2 independently included BMI (with normal weight as reference) and SPPB categories (with intact physical performance as reference), respectively. BMI and SPPB categories were jointly included in model 3 and covariates were added. After creating eight dummy variables by combining 4 $\mathrm{BMI} \times 2 \mathrm{SPPB}$ categories, these and all covariates were included in model 4 with normal weight and intact physical performance as a reference, and use of a private car was added in model 5 with car driver as a reference. SPSS Statistics 22 (IBM, Armonk, NY, USA) was used for all statistical analyses. The statistical significance was set at $P<0.05$.

\section{Results}

Table 1 shows participants' characteristics according to both BMI and SPPB categories. Participants with a BMI $\geq 30.0 \mathrm{~kg} / \mathrm{m}^{2}$ were more often women and younger than subjects with a lower BMI. The most prevalent use of a private car in participants with normal weight was driving; whereas in those with low weight, obesity, or who were overweight, being a passenger was most common. Those with impaired lower extremity performance were older and had a higher BMI, more chronic diseases, less education, and more restricted life-space area than those with intact lower extremity performance.

Table 2 shows the results of multivariate Poisson regression analyses having life-space restriction at the baseline. Among those with impaired performance, all BMI groups had a significantly higher risk of restricted life-space than the group with normal weight and intact physical performance in the fully adjusted model (PR varies between 2.71 and 3.31).

The flow of participants is indicated in Fig. 1. The 581 older people without life-space restriction at baseline contributed 1033 person-years during the two-year follow-up. During follow-up, incident life-space restrictions were reported by $28.3 \%$ participants (event rate 164 per 1000 person-years). Figure 2 shows the incidence rates of life-space restriction at each follow-up according to the combined BMI and SPPB categories. The incidence rate was $21.8 \%(18.1 \%-28.4 \%$ among BMI categories) among those with intact lower extremity performance and $47.4 \%$ (42.3-65.0\% among BMI categories) among those with an impaired performance from baseline to two-year follow-up.

Table 3 shows the results of multiple Cox's proportional hazard regression analyses. Subjects with a BMI $\geq 30.0 \mathrm{~kg} / \mathrm{m}^{2}$ were 1.73 (95\% CI, 1.05-2.86) times more likely to develop life-space restriction compared with people with a BMI $23.0-24.9 \mathrm{~kg} / \mathrm{m}^{2}$. The corresponding figure was 2.44 (95\% CI, 1.80-3.32) among people with impaired lower extremity performance vs. those with intact performance. In the model including both BMI and SPPB categories and covariates, SPPB remained significant (HR 2.39, 95\% CI 1.75-3.27) but the effect of BMI was attenuated $\left(B M I \geq 30.0 \mathrm{~kg} / \mathrm{m}^{2}: \mathrm{HR} 1.65,95 \% \mathrm{CI}\right.$ 0.99-2.75). The model examining the combined effect of BMI and SPPB catergories revealed that subjects with both obesity and impaired lower extremity performance had the highest hazard for incident life-space restriction (HR 3.79, 95\% CI 1.84-7.83), followed by those with impaired lower extremity performance only (HR 2.50, 95\% CI 1.18-5.29), and those with obesity only (HR 1.70, 95\% CI, 0.88-3.29), after adjusting for age, sex, number of chronic diseases, and year of education. In the full model including combined BMI $\times$ SPPB categories, use of a private car, and covariates, those overweight and obese subjects with impaired lower extremity performance remained significant (HR 2.77 and 3.57, respectively), and private car passengers had a significantly higher hazard for incident life-space restriction than car drivers (HR 1.96, 95\% CI, 1.27-3.01). Age, numbers of chronic diseases, and years of education were statistically significant as potential confounding factors; however, sex was not. 
Table 1 Descriptive baseline data of participants according to BMI and lower extremity performance

\begin{tabular}{|c|c|c|c|c|c|c|c|c|}
\hline \multirow[t]{2}{*}{ Variables } & $\begin{array}{l}\text { Low weight } \\
(\mathrm{BMI}<23.0)\end{array}$ & $\begin{array}{l}\text { Normal weight } \\
\text { (BMl 23.0-24.9) }\end{array}$ & $\begin{array}{l}\text { Overweight } \\
\text { (BMl 25.0-29.9) }\end{array}$ & $\begin{array}{l}\text { Obese } \\
(\mathrm{BMI} \geq 30.0)\end{array}$ & $P$ & $\begin{array}{l}\text { Intact LEP } \\
\text { (SPPB 10-12) }\end{array}$ & $\begin{array}{l}\text { Impaired LEP } \\
\text { (SPPB 0-9) }\end{array}$ & $P$ \\
\hline & $n=156$ & $n=166$ & $n=375$ & $n=126$ & & $n=523$ & $n=300$ & \\
\hline \multicolumn{9}{|l|}{ Characteristics } \\
\hline Age (year), $M \pm S D$ & $81.2 \pm 4.3$ & $79.9 \pm 4.2$ & $80.0 \pm 4.3$ & $79.4 \pm 4.1$ & $.003^{\mathrm{a}}$ & $79.7 \pm 4.2$ & $80.8 \pm 4.3$ & $<.001^{\mathrm{a}}$ \\
\hline Women, $n(\%)$ & $100(64.1 \%)$ & $88(53.0 \%)$ & $226(60.3 \%)$ & $97(77.0 \%)$ & $<.001^{b}$ & $318(60.8 \%)$ & $193(64.3 \%)$ & $.315^{b}$ \\
\hline Height $(\mathrm{cm}), M \pm S D$ & $163.8 \pm 9.0$ & $166.7 \pm 9.0$ & $164.9 \pm 9.0$ & $162.4 \pm 7.7$ & $<.001^{\mathrm{a}}$ & $165.0 \pm 8.4$ & $164.0 \pm 9.7$ & $.104^{a}$ \\
\hline Body weight $(\mathrm{kg}), M \pm S D$ & $56.8 \pm 8.3$ & $66.9 \pm 7.4$ & $73.7 \pm 8.4$ & $86.9 \pm 11.0$ & $<.001^{\mathrm{a}}$ & $70.8 \pm 11.8$ & $71.7 \pm 13.8$ & $.317^{a}$ \\
\hline $\mathrm{BMI}(\mathrm{kg} / \mathrm{m} 2), M \pm S D$ & $21.1 \pm 1.6$ & $24.0 \pm 0.5$ & $27.0 \pm 1.4$ & $32.9 \pm 2.9$ & $<.001^{\mathrm{a}}$ & $26.0 \pm 3.8$ & $26.6 \pm 4.3$ & $.029^{a}$ \\
\hline Chronic diseases (n), Med (IQR) & $4(4)$ & $4(3)$ & $4(3)$ & $4(3)$ & $.007^{c}$ & $4(3)$ & $5(4)$ & $<.001^{\circ}$ \\
\hline Education (year), Med (IQR) & $9(5)$ & $9(5)$ & $8(5)$ & $8(5)$ & $.060^{c}$ & $9(5)$ & $8(4)$ & $<.001^{\mathrm{c}}$ \\
\hline \multicolumn{9}{|l|}{ Life-space } \\
\hline $\begin{array}{l}\text { Maximal independent LS (score), } \\
\text { Med (IQR) }\end{array}$ & $4(2)$ & $5(1)$ & $4(2)$ & $4(4)$ & $.019^{c}$ & $5(1)$ & $4(4)$ & $<.001^{\circ}$ \\
\hline \multicolumn{9}{|l|}{ Short Physical Performance Battery } \\
\hline Total (score), Med (IQR) & $11.0(3.0)$ & $11.0(3.0)$ & $10.0(3.0)$ & $10.0(3.0)$ & $.006^{c}$ & $11.0(1.0)$ & $8.0 .0)$ & $<.001^{\mathrm{c}}$ \\
\hline Impaired (SPPB 0-9), n (\%) & $56(35.9 \%)$ & $48(28.9 \%)$ & $144(38.4 \%)$ & $52(41.3 \%)$ & $.113^{b}$ & - & - & \\
\hline \multicolumn{9}{|l|}{ Use of a private car, $n$ (\%) } \\
\hline Car driver & $51(32.7 \%)$ & $78(47.0 \%)$ & $160(42.7 \%)$ & $37(29.4 \%)$ & $.006^{b}$ & $246(47.0 \%)$ & $80(26.7 \%)$ & $<.001^{b}$ \\
\hline Private car passenger & $77(49.4 \%)$ & $66(39.8 \%)$ & $165(44.0 \%)$ & 75 (59.5\%) & & $216(41.3 \%)$ & $167(55.7 \%)$ & \\
\hline No use of a private car & $28(17.9 \%)$ & $22(13.3 \%)$ & $50(13.3 \%)$ & $14(11.1 \%)$ & & $61(11.7 \%)$ & $53(17.7 \%)$ & \\
\hline
\end{tabular}

$n=823$

$M$ mean, $S D$ standard deviation, Med median, IQR interquartile range, $B M I$ body mass index, $L E P$ lower extremity performance, SPPB short physical performance battery, $L S$ life-space

${ }^{\mathrm{a}}$ one-way analysis of variance; ${ }^{\mathrm{b}}$ chi-square test; ${ }^{\mathrm{c}}$ Kruskal-Wallis test; ${ }^{\mathrm{d}}$ Mann-Whitney $U$ test

\section{Discussion}

This two-year prospective study reveals that community-dwelling older people who are overweight or obese and also have impaired lower extremity performance exhibit a higher risk of both current and future life-space restriction than those who are not overweight or obese, with or without impaired lower extremity performance. Furthermore, not driving a car also renders older people vulnerable to having a restricted life-space. These results suggest that we should approach the subject of life-space mobility in older people from the aspects of both physical characteristics and transportation options.

We found that impaired lower extremity performance was a crucial contributing factor to incident life-space restriction. Previous cross-sectional studies have established that a good lower extremity performance in older adults is an important factor underlying better life-space mobility [4-6]. Lower extremity performance also contributes to incident mobility disability and limitations in ADL [27-29]. Most previous longitudinal studies have assessed the self-reported ability to perform specific tasks (e.g., walking a half mile, climbing stairs, using toilets, or bathing) with or without difficulties or help. A life-space assessment has the advantage of revealing how far participants move, which is determined by their internal physiologic capacity and their immediate environmental challenges [3]. The results of the present study suggest that lower extremity performance may correspond to the internal physiological capacity contributing to individuals' life-space, and it may also play an important role when addressing environmental challenges.

Our results support previous cross-sectional study findings that highly obese older people (BMI $\geq 35.0 \mathrm{~kg} /$ $\mathrm{m}^{2}$ ) were significantly more likely to attain low life-space mobility scores [5]. Furthermore, systematic reviews and meta-analyses of longitudinal studies have revealed that obesity was a strong predictor of long-term risk for mobility disability and limitations in ADL [30, 31]. Excess body weight in older individuals may cause a mechanical burden potentially leading to altered walking patterns with lower energetic efficiency [32] and overall strain experienced when in motion. Additionally, increasing body weight triggers lower extremity pain (especially in the knee and ankle), which may contribute to mobility disability in older people. [30]. The joint pain may induce fear of movement and avoidance of weight-bearing tasks that trigger pain [33]. These negative consequences associated with obesity may correspond to a poor internal physiological capacity, making it difficult to tackle 
Table 2 Association of BMI and lower extremity performance with life-space restriction (cross-sectional analysis)

\begin{tabular}{|c|c|c|c|c|c|c|c|c|c|c|}
\hline & \multicolumn{2}{|c|}{ Model 1} & \multicolumn{2}{|c|}{ Model 2} & \multicolumn{2}{|c|}{ Model $3^{a}$} & \multicolumn{2}{|c|}{ Model $4^{a}$} & \multicolumn{2}{|c|}{ Model $5^{\text {a }}$} \\
\hline & $P R$ & $95 \% \mathrm{Cl}$ & $P R$ & $95 \% \mathrm{Cl}$ & $\mathrm{PR}$ & $95 \% \mathrm{Cl}$ & $P R$ & $95 \% \mathrm{Cl}$ & $P R$ & $95 \% \mathrm{Cl}$ \\
\hline \multicolumn{11}{|l|}{ Single association } \\
\hline \multicolumn{11}{|l|}{ BMI } \\
\hline$<23$ & 1.36 & $(0.93,1.98)$ & & & 1.03 & $(0.74,1.44)$ & & & & \\
\hline $23-25$ & 1.00 & & & & 1.00 & & & & & \\
\hline $25-30$ & 1.21 & $(0.86,1.69)$ & & & 1.01 & $(0.75,1.36)$ & & & & \\
\hline$\geq 30$ & 1.68 & $(1.16,2.44)$ & & & 1.24 & $(0.89,1.73)$ & & & & \\
\hline \multicolumn{11}{|c|}{ Lower extremity performance } \\
\hline Intact (SPPB 10-12) & & & 1.00 & & 1.00 & & & & & \\
\hline Impaired (SPPB 0-9) & & & 3.31 & $(2.62,4.18)$ & 2.58 & $(2.05,3.25)$ & & & & \\
\hline \multicolumn{11}{|l|}{ Combined association } \\
\hline \multicolumn{11}{|l|}{ Intact LEP with BMI } \\
\hline$<23$ & & & & & & & 1.15 & $(0.60,2.23)$ & 1.09 & $(0.56,2.11)$ \\
\hline $23-25$ & & & & & & & 1.00 & & 1.00 & \\
\hline $25-30$ & & & & & & & 1.18 & $(0.66,2.11)$ & 1.19 & $(0.67,2.12)$ \\
\hline$\geq 30$ & & & & & & & 1.48 & $(0.77,2.82)$ & 1.43 & $(0.76,2.71)$ \\
\hline \multicolumn{11}{|l|}{ Impaired LEP with BMI } \\
\hline$<23$ & & & & & & & 3.03 & $(1.73,5.31)$ & 2.71 & $(1.55,4.74)$ \\
\hline $23-25$ & & & & & & & 3.14 & $(1.74,5.67)$ & 2.73 & $(1.53,4.89)$ \\
\hline $25-30$ & & & & & & & 2.89 & $(1.68,4.97)$ & 2.66 & $(1.56,4.53)$ \\
\hline$\geq 30$ & & & & & & & 3.55 & $(2.02,6.27)$ & 3.31 & $(1.89,5.81)$ \\
\hline \multicolumn{11}{|l|}{ Use of a private car } \\
\hline Car driver & & & & & & & & & 1.00 & \\
\hline Private car passenger & & & & & & & & & 2.07 & $(1.39,3.07)$ \\
\hline No use a private car & & & & & & & & & 2.15 & $(1.41,3.28)$ \\
\hline
\end{tabular}

environmental challenges. Therefore, life-space in obese people is more likely to be restricted. After adjusting for lower extremity performance and covariates, however, the statistical significance of obesity was lost in the current study. As indicated above, BMI considerably impacts lower extremity performance and chronic diseases and may be a confounding factor itself [34].

The principal finding of the present study was that impaired lower extremity performance combined with overweight or obesity increased the risk of incident life-space restriction more than either one alone. Recently, dynapenic obesity, a condition of coexisting low muscle strength and obesity, received attention as a relative or contributing factor for falls [35], a decline in physical function [36, 37], and limitations in mobility and ADL [36]. Stenholm et al. [36] showed that obese older persons with low knee extensor muscle strength experienced significantly greater declines in walking speed and mobility than persons with either condition alone over a six-year follow-up. People with poor lower extremity muscular function may not have enough physical capacity to carry their body mass, and, consequently, their life-space mobility declines even further than those with only obesity or impaired lower extremity performance. Among people with impaired lower extremity performance, its negative impact was compensated by the use of a private car in those with low or normal weight but not in those who were overweight or obese. These results suggest that improving alternative transportation options may aid those people with low or normal weight to maintain their life-space even if their lower extremity performance is impaired. However, for obese people improvements in transportation options alone may not be sufficient to prevent life-space restriction.

The present study revealed that driving one's private car was important for maintaining life-space in community-dwelling older people. This result is in line with previous findings showing an association between 


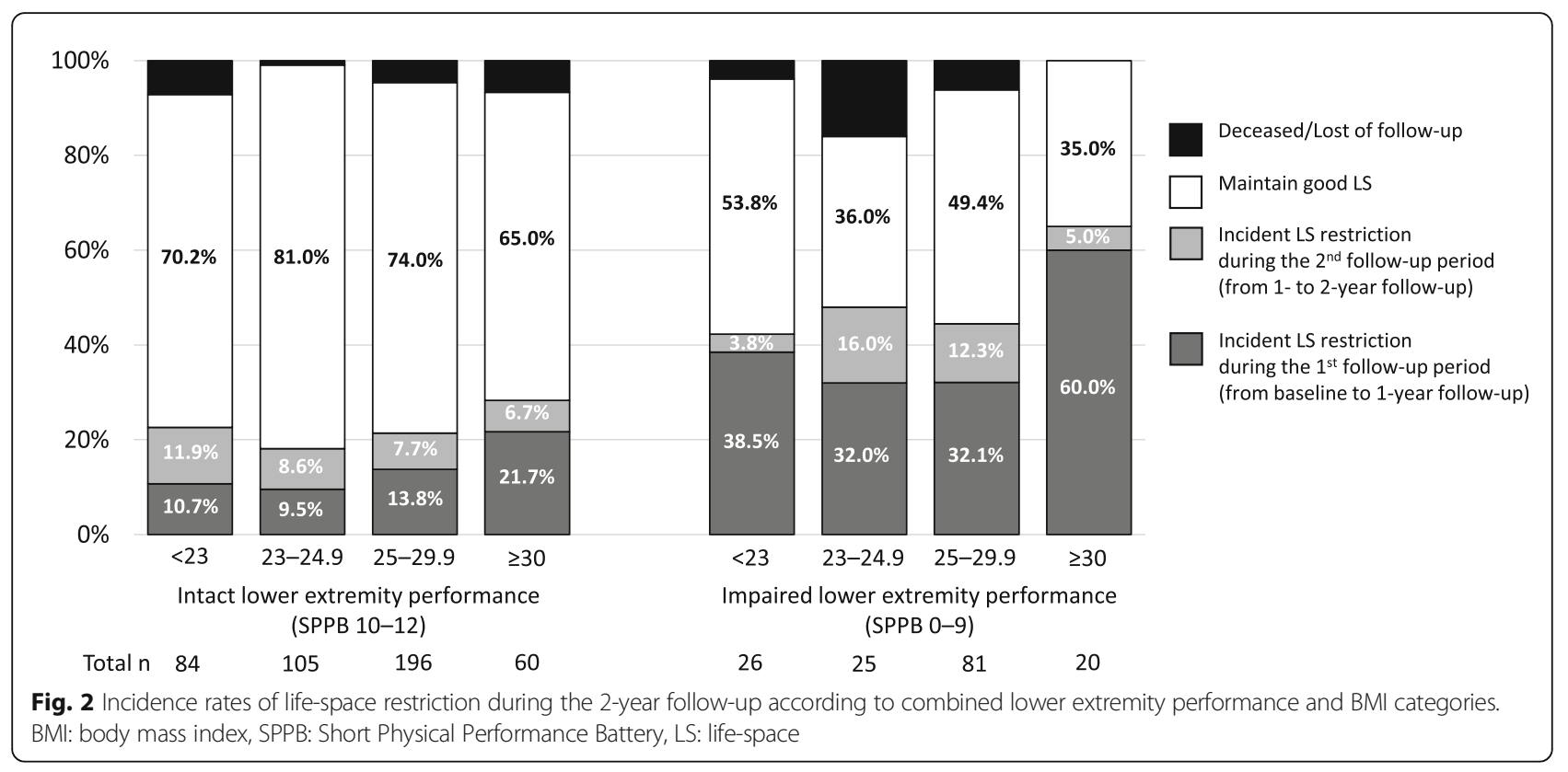

Table 3 Effect of BMI and lower extremity performance on incident life-space restriction (longitudinal analysis)

\begin{tabular}{|c|c|c|c|c|c|c|c|c|c|c|}
\hline & \multicolumn{2}{|c|}{ Model 1} & \multicolumn{2}{|c|}{ Model 2} & \multicolumn{2}{|c|}{ Model $3^{a}$} & \multicolumn{2}{|c|}{ Model $4^{a}$} & \multicolumn{2}{|c|}{ Model $5^{a}$} \\
\hline & $\mathrm{HR}$ & $95 \% \mathrm{Cl}$ & $\mathrm{HR}$ & $95 \% \mathrm{Cl}$ & $\mathrm{HR}$ & $95 \% \mathrm{Cl}$ & $\mathrm{HR}$ & $95 \% \mathrm{Cl}$ & $\mathrm{HR}$ & $95 \% \mathrm{Cl}$ \\
\hline \multicolumn{11}{|l|}{ Single effect } \\
\hline \multicolumn{11}{|l|}{ BMl } \\
\hline$<23$ & 1.19 & $(0.72,1.97)$ & & & 1.03 & $(0.62,1.70)$ & & & & \\
\hline $23-25$ & 1.00 & & & & 1.00 & & & & & \\
\hline $25-30$ & 1.21 & $(0.80,1.84)$ & & & 1.07 & $(0.70,1.62)$ & & & & \\
\hline$\geq 30$ & 1.73 & $(1.05,2.86)$ & & & 1.65 & $(0.99,2.75)$ & & & & \\
\hline \multicolumn{11}{|c|}{ Lower extremity performance } \\
\hline Intact (SPPB 10-12) & & & 1.00 & & 1.00 & & & & & \\
\hline Impaired (SPPB 0-9) & & & 2.44 & $(1.80,3.32)$ & 2.39 & $(1.75,3.27)$ & & & & \\
\hline \multicolumn{11}{|l|}{ Combined effect } \\
\hline \multicolumn{11}{|l|}{ Intact LEP with BMI } \\
\hline$<23$ & & & & & & & 1.02 & $(0.54,1.93)$ & 1.00 & $(0.53,1.89)$ \\
\hline $23-25$ & & & & & & & 1.00 & & 1.00 & \\
\hline $25-30$ & & & & & & & 1.06 & $(0.61,1.84)$ & 1.06 & $(0.61,1.83)$ \\
\hline$\geq 30$ & & & & & & & 1.70 & $(0.88,3.29)$ & 1.78 & $(0.92,3.47)$ \\
\hline \multicolumn{11}{|l|}{ Impaired LEP with BMI } \\
\hline$<23$ & & & & & & & 2.40 & $(1.16,4.97)$ & 2.03 & $(0.98,4.22)$ \\
\hline $23-25$ & & & & & & & 2.50 & $(1.18,5.29)$ & 1.91 & $(0.90,4.08)$ \\
\hline $25-30$ & & & & & & & 2.57 & $(1.46,4.52)$ & 2.77 & $(1.57,4.87)$ \\
\hline$\geq 30$ & & & & & & & 3.79 & $(1.84,7.83)$ & 3.57 & $(1.72,7.38)$ \\
\hline \multicolumn{11}{|l|}{ Use of a private car } \\
\hline Car driver & & & & & & & & & 1.00 & \\
\hline Private car passenger & & & & & & & & & 1.96 & $(1.27,3.01)$ \\
\hline No use a private car & & & & & & & & & 1.51 & $(0.87,2.62)$ \\
\hline
\end{tabular}

581 people without life-space restriction at the baseline contributed 1033 person-years during two-year follow-up

$H R$ hazard ratio, $C l$ confidence interval, $B M I$ body mass index, LEP lower extremity performance, SPPB short physical performance battery

${ }^{a}$ Adjusting for sex, age, chronic diseases, and education 
driving a car and a larger life-space [18, 19]. Shah et al. [19] reported that people who were licensed to drive were less likely to be restricted in their life-space over the average four-year follow-up compared to people without a driver's license. The results of this study have also revealed that use of a private car, not as a driver but as a passenger, was associated with life-space restriction independently from individuals' physical characteristics, which is consistent with a previous cross-sectional study [20]. However, the risk of incident life-space restriction was increased without statistical significance in people who did not use a private car in the present study. Even among those people, some may have frequently used public transportation modes, which are also associated with life-space $[38,39]$. According to a previous cross-sectional study, the risk of life-space restriction in public transportation users did not differ significantly from private car drivers among older people without walking difficulties [20]. Further studies taking into consideration the use of public transportation modes are warranted.

The strengths of the present study were the use of high-quality longitudinal data with an excellent follow-up rate for a large population-based sample and exploring the contributing factors of life-space restriction, which is a topical issue, by focusing on both modifiable physical factors and an environmental factor. However, several study limitations warrant further consideration. Firstly, BMI was calculated from self-reported height and weight, not from objective measurements. Secondly, because of the bias of the participants' BMI distribution, we classified those with BMI $<23.0 \mathrm{~kg} / \mathrm{m}^{2}$ as low weight. However, this classification does not conform to the WHO guidelines [22] which state that a BMI $<18.5 \mathrm{~kg} / \mathrm{m}^{2}$ should be classified as underweight. This change may have resulted in an underestimation of the contribution of low weight on incident life-space restriction. Thirdly, we did not collect BMI and SPPB data at the follow-ups. Therefore, we could not address whether a change in BMI or lower extremity performance in older age contributes to incident life-space restriction.

\section{Conclusions}

Community-dwelling older adults with impaired lower extremity performance have an increased risk of both current and future life-space restriction, especially when overweight or obese. Furthermore, not driving a private car renders older people vulnerable to life-space restriction. Programs to improve lower extremity performance and to prevent excess body weight may have the potential to maintain life-space and even prevent social isolation, a potential consequence of restricted life-space mobility. Improvements in alternative transportation options, especially for older people who do not drive a car, is also essential.

\section{Abbreviations}

ADL: Activities of daily living; BMI: Body mass index; Cl: Confidence interval; HR: Hazard ratio; LISPE: Life-Space Mobility in Old Age; PR: Prevalence ratio; SPPB: Short Physical Performance Battery

\section{Acknowledgements}

We would like to thank the study participants. The Gerontology Research Center (GEREC) is a joint effort between University of Jyväskylä and University of Tampere, Finland.

\section{Funding}

This work was supported by Grant-in-Aid for JSPS Fellows (grant number 13 J00010), Grant-in-Aid for Scientific Research (KAKENHI) from the Japanese Society for the Promotion of Science (grant number 16 K16595), Academy of Finland (future of living and housing program ASU-LIVE, grant number 255403), and Finnish Ministry of Education and Culture. The funders had no role in study design, data collection and analysis, decision to publish, or preparation of the manuscript.

\section{Availability of data and materials}

Due to ethical and legal restrictions, data are available on request from the LISPE research group. To ensure the protection of privacy and compliance with relevant Finnish laws, researchers interested in using the data must obtain approval for data usage. Additional restrictions and conditions may apply. To request the data please contact Professor Taina Rantanen (taina.rantanen@jyu.fi)

\section{Authors' contributions}

$\Pi$ T: conception, design, analysis and interpretation of the data, and writing the article; MR, EP, and AV: conception, design, data collection, and critical revision of the article; TR: conception, design, data collection, critical revision of the article, and principal investigator for the LISPE project. All authors approved the final draft submitted.

\section{Ethics approval and consent to participate}

The LISPE project was approved by the Ethical Committee of the University of Jyväskylä, Finland. All participants gave their written informed consent to take part in the study.

\section{Consent for publication}

Not Applicable.

\section{Competing interests}

The authors declare that they have no competing interest.

\section{Publisher's Note}

Springer Nature remains neutral with regard to jurisdictional claims in published maps and institutional affiliations.

\section{Author details}

${ }^{1}$ Center for Preventive Medical Sciences, Chiba University, 1-8-1 Inohana, Chuo Ward, Chiba City, Chiba 260-8670, Japan. ${ }^{2}$ Gerontology Research Center, Faculty of Sport and Health Sciences, University of Jyvaskyla, PO Box 35, Fl-40014 Jyväskylä, Finland.

Received: 6 February 2018 Accepted: 18 October 2018

Published online: 08 November 2018

\section{References}

1. Brown CJ, Flood KL. Mobility limitation in the older patient: a clinical review. JAMA. 2013;310:1168-77.

2. La Grow S, Yeung P, Towers A, Alpass F, Stephens C. The impact of mobility on quality of life among older persons. J Aging Health. 2013;25:723-36.

3. Rantanen T, Portegijs E, Viljanen A, Eronen J, Saajanaho M, Tsai LT, et al. Individual and environmental factors underlying life space of older peoplestudy protocol and design of a cohort study on life-space mobility in old age (LISPE). BMC Public Health. 2012;12:1018. 
4. Baker PS, Bodner EV, Allman RM. Measuring life-space mobility in community-dwelling older adults. J Am Geriatr Soc. 2003;51:1610-4.

5. Al Snih S, Peek KM, Sawyer P, Markides KS, Allman RM, Ottenbacher KJ. Lifespace mobility in Mexican Americans aged 75 and older. J Am Geriatr Soc. 2012;60:532-7.

6. Portegijs E, Rantakokko M, Mikkola TM, Viljanen A, Rantanen T. Association between physical performance and sense of autonomy in outdoor activities and life-space mobility in community-dwelling older people. J Am Geriatr Soc. 2014;62:615-21

7. Rantakokko M, Portegijs E, Viljanen A, Iwarsson S, Rantanen T. Life-space mobility and quality of life in community-dwelling older people. J Am Geriatr Soc. 2013;61:1830-2.

8. Bentley JP, Brown CJ, McGwin G Jr, Sawyer P, Allman RM, Roth DL. Functional status, life-space mobility, and quality of life: a longitudinal mediation analysis. Qual Life Res. 2013;22:1621-32.

9. Lo AX, Rundle AG, Buys D, Kennedy RE, Sawyer P, Allman RM, et al. Neighborhood disadvantage and life-space mobility are associated with incident falls in community-dwelling older adults. J Am Geriatr Soc. 2016;64: 2218-25.

10. Portegijs E, Rantakokko M, Viljanen A, Sipila S, Rantanen T. Identification of older people at risk of ADL disability using the life-space assessment: a longitudinal cohort study. J Am Med Dir Assoc. 2016;17:410-4.

11. Silberschmidt S, Kumar A, Raji MM, Markides K, Ottenbacher KJ, Al SS. Lifespace mobility and cognitive decline among Mexican Americans aged 75 years and older. J Am Geriatr Soc. 2017;65:1514-20.

12. Kennedy RE, Williams CP, Sawyer P, Lo AX, Connelly K, Nassel A, et al. Lifespace predicts health care utilization in community-dwelling older adults. J Aging Health. 2017. https://doi.org/10.1177/0898264317730487.

13. Kennedy RE, Sawyer P, Williams CP, Lo AX, Ritchie CS, Roth DL, et al. Lifespace mobility change predicts 6-month mortality. J Am Geriatr Soc. 2017; 65:833-8.

14. Polku H, Mikkola TM, Rantakokko M, Portegijs E, Tormakangas T, Rantanen T, et al. Self-reported hearing difficulties and changes in life-space mobility among community-dwelling older adults: a two-year follow-up study. BMC Geriatr. 2015;15:121.

15. Poranen-Clark T, von Bonsdorff MB, Rantakokko M, Portegiis E, Eronen J, Pynnonen K, et al. The temporal association between executive function and life-space mobility in old age. J Gerontol A Biol Sci Med Sci. 2018;73: 835-9.

16. Portegijs E, Rantakokko M, Viljanen A, Sipila S, Rantanen T. Is frailty associated with life-space mobility and perceived autonomy in participation outdoors? A longitudinal study. Age Ageing. 2016;45:550-3.

17. Collia DV, Sharp J, Giesbrecht L. The 2001 National Household Travel Survey: a look into the travel patterns of older Americans. J Saf Res. 2003:34:461-70.

18. Stalvey BT, Owsley C, Sloane ME, Ball K. The life space questionnaire: a measure of the extent of mobility of older adults. J Appl Gerontol. 1999;18: 460-78.

19. Shah RC, Maitra K, Barnes LL, James BD, Leurgans S, Bennett DA. Relation of driving status to incident life space constriction in community-dwelling older persons: a prospective cohort study. J Gerontol A Biol Sci Med Sci. 2012:67:984-9.

20. Viljanen A, Mikkola TM, Rantakokko M, Portegijs E, Rantanen T. The association between transportation and life-space mobility in communitydwelling older people with or without walking difficulties. J Aging Health. 2016;28:1038-54

21. Ritchie CS, Locher JL, Roth DL, McVie T, Sawyer P, Allman R. Unintentional weight loss predicts decline in activities of daily living function and lifespace mobility over 4 years among community-dwelling older adults. J Gerontol A Biol Sci Med Sci. 2008;63:67-75.

22. Obesity: preventing and managing the global epidemic. Report of a WHO consultation. World Health Organ Tech Rep Ser. 2000;894:i-xii, 1-253.

23. Vellas B, Villars H, Abellan G, Soto ME, Rolland Y, Guigoz Y, et al. Overview of the MNA--its history and challenges. J Nutr Health Aging. 2006;10:456-63 discussion 63-5.

24. Guralnik JM, Simonsick EM, Ferrucci L, Glynn RJ, Berkman LF, Blazer DG, et al. A short physical performance battery assessing lower extremity function: association with self-reported disability and prediction of mortality and nursing home admission. J Gerontol. 1994;49:M85-94.

25. Mänty M, Sihvonen S, Hulkko T, Lounamaa A. läkkäiden Henkilöiden Kaatumistapaturmat. Opas Kkaatumisten ja Murtumien Ehkäisyyn, 2nd Ed. Kansanterveyslaitoksen julkaisuja: Helsinki; 2007.
26. Zhang J, Yu KF. What's the relative risk? A method of correcting the odds ratio in cohort studies of common outcomes. JAMA. 1998;280:1690-1.

27. Guralnik JM, Ferrucci L, Simonsick EM, Salive ME, Wallace RB. Lowerextremity function in persons over the age of 70 years as a predictor of subsequent disability. N Engl J Med. 1995;332:556-61.

28. Deshpande N, Metter EJ, Guralnik J, Bandinelli S, Ferrucci L. Predicting 3-year incident mobility disability in middle-aged and older adults using physical performance tests. Arch Phys Med Rehabil. 2013;94:994-7.

29. den Ouden ME, Schuurmans MJ, Arts IE, van der Schouw YT. Physical performance characteristics related to disability in older persons: a systematic review. Maturitas. 2011;69:208-19.

30. Vincent HK, Vincent KR, Lamb KM. Obesity and mobility disability in the older adult. Obes Rev. 2010;11:568-79.

31. Backholer K, Wong E, Freak-Poli R, Walls HL, Peeters A. Increasing body weight and risk of limitations in activities of daily living: a systematic review and meta-analysis. Obes Rev. 2012;13:456-68.

32. Ko S, Stenholm S, Ferrucci L. Characteristic gait patterns in older adults with obesity--results from the Baltimore longitudinal study of aging. J Biomech. 2010;43:1104-10.

33. Gooberman-Hill R, Woolhead G, Mackichan F, Ayis S, Williams S, Dieppe P. Assessing chronic joint pain: lessons from a focus group study. Arthritis Rheum. 2007:57:666-71.

34. Sharts-Hopko NC, Sullivan MP. Obesity as a confounding health factor among women with mobility impairment. J Am Acad Nurse Pract. 2003;15: 438-43.

35. Scott D, Sanders KM, Aitken D, Hayes A, Ebeling PR, Jones G. Sarcopenic obesity and dynapenic obesity: 5-year associations with falls risk in middleaged and older adults. Obesity (Silver Spring). 2014;22:1568-74.

36. Stenholm S, Alley D, Bandinelli S, Griswold ME, Koskinen S, Rantanen T, et al. The effect of obesity combined with low muscle strength on decline in mobility in older persons: results from the InCHIANTI study. Int J Obes. 2009; 33:635-44.

37. Bouchard DR, Janssen I. Dynapenic-obesity and physical function in older adults. J Gerontol A Biol Sci Med Sci. 2010;65:71-7.

38. Murata C, Kondo T, Tamakoshi K, Yatsuya H, Toyoshima H. Factors associated with life space among community-living rural elders in Japan. Public Health Nurs. 2006:23:324-31.

39. Wilkie R, Peat G, Thomas E, Croft P. Factors associated with restricted mobility outside the home in community-dwelling adults ages fifty years and older with knee pain: an example of use of the international classification of functioning to investigate participation restriction. Arthritis Rheum. 2007:57:1381-9.

Ready to submit your research? Choose BMC and benefit from

- fast, convenient online submission

- thorough peer review by experienced researchers in your field

- rapid publication on acceptance

- support for research data, including large and complex data types

- gold Open Access which fosters wider collaboration and increased citations

- maximum visibility for your research: over $100 \mathrm{M}$ website views per year

At $\mathrm{BMC}$, research is always in progress.

Learn more biomedcentral.com/submissions 